\title{
Geomorphic Surfaces of Eastern Lake Urmia Playa and their Influence on Dust Storms
}

\section{${ }^{1}$ MAIS ALKHAYER; ${ }^{1}$ MOSTAFA KARIMIAN EGHBAL; ${ }^{2 *}$ NIKOU HAMZEHPOUR}

\author{
${ }^{I}$ Department of Soil Science, Faculty of Agriculture Tarbiat Modares University, Tehran, Iran \\ ${ }^{2}$ Department of Soil Sciences, Faculty of Agriculture, University of Maragheh, Postal Code: 55181-83111, Maragheh, Iran. \\ "Corresponding Author Email: nhamzehpour@maragheh.ac.ir; Fax: +984137276060
}

\begin{abstract}
Lake Urmia is one of the most important salt lakes in the world and the largest in Iran. At present, because of the recession of Lake Urmia and deposition of lacustrine sediments on the lake bed, a large part of the surrounding areas has become flat with several playa surfaces. So far, there have been very few studies related to Lake Urmia playa and its geomorphology. Therefore, the aim of this research was to field study of playa surfaces of Lake Urmia in its eastern part and also to identify areas susceptible to wind erosion. In this study, different playa surfaces from the northeast to the south of the lake were identified and mapped using satellite imagery. Then, boundaries of the mapped surfaces were checked during field observations. Moreover, physical soil properties, such as texture, bulk density, saturation percentage, resistancy, particle size distribution and soil aggregate stability, were determined. Next, the correlation of the studied properties with each surface resistance to wind erosion was investigated, and finally the geomorphic surfaces of Urmia Playa and their resistance to wind erosion were mapped using ARCGIS software. Based on the results, the study area included agricultural lands, shrub-grass zones, sand and gravel zones, mud-clay salt flats, sand-salt crusts, puffy grounds, delta-fans and wet zones. Results showed that approximately $25 \%$ of the surfaces had high resistance to wind erosion and they are therefore stable surfaces with no potential for generating dust in the future. About $35 \%$ of the surfaces were strongly susceptible to wind erosion, highly prone to generate saline dusts and sand storms. These areas were located in the east and southeast of the lake. Also, $40 \%$ of playa surfaces had moderate resistance to wind erosion. These areas can become very sensitive to wind erosion if ground water depth or the roughness of the surface changes. In conclusion, sandy-salt surfaces in the east and southeast of the lake are the most susceptible to wind erosion with high potential for generating dust, sand, and salt storms, which can affect agricultural lands and human health in the near future.
\end{abstract}

\section{DOI: https://dx.doi.org/10.4314/jasem.v23i8.15}

Copyright: Copyright $(C 2019$ Alkhayer et al. This is an open access article distributed under the Creative Commons Attribution License (CCL), which permits unrestricted use, distribution, and reproduction in any medium, provided the original work is properly cited.

Dates: Received: 18 August 2019; Revised: 19 August 2019; 25 August 2019

Keywords: dust, erosion, geomorphology, Inceptisols, playa, Lake Urmia

Identifying saline lands, mapping them and properly managing them are of great importance in arid and semiarid regions. Secondary salinization of agricultural lands due to salt spread by dust and irrigation water reduces the productivity of soils in arid regions every year and affects human health (Chen et al., 2009; Middleton, 2017).

Lake Urmia is one of the most important salt lakes in the world and the biggest in Iran and in fact in the entire Middle East (Karbasi et al., 2010). Lake Urmia is located in the northwest of Iran. The average altitude of the lake is $1276 \mathrm{~m}$ and the salt content varies from 185 to $300 \mathrm{~g} /$ lit (Hoseinpour et al., 2010). Over the past few years, as a result of Lake Urmia drying up, the salinization of agricultural lands is spreading at a fast rate (Hamzehpour and Bogaert, 2017). This is happening due to a change in saline-non-saline groundwater interface and also due to dust movement from exposed salt surfaces that were once part of the lake bed. As a population of almost six million is directly and indirectly affected by the consequences of Lake Urmia drying up (SEDAC, 2010), the threat of salinization and thereafter desertification of agricultural lands require careful attention and proper action is needed to be promptly taken. For thousands of years, the Urmia lowland has been under water, and all kinds of sediments from the surrounding lands have been washed into the lake bed, turning it to a hypersaline lake with a salinity of more than $100 \mathrm{dS} / \mathrm{m}$. Over the past few decades, due to reduced amounts of water flow to the lake and also due to decreased precipitation, water depth and the lake's surface area has decreased dramatically (Shadkam et al., 2016; Farokhnia and Morid, 2014; Kakahaji et al., 2013; Hassanzadeh et al., 2012). Water withdrawal from the lake shores has created vast barren areas around it. Remote sensing studies of recent images of Lake Urmia have shown that the Lake Urmia surface area has decreased from $5433 \mathrm{~km}^{2}$ in 1998 to the current 
$1798 \mathrm{~km}^{2}$. This means that an area of almost $3600 \mathrm{~km}^{2}$ has been exposed in recent years.

By definition, playas are low flat areas in closed basins in arid regions which were once underlain by lacustrine sediments. Playas form during higher precipitation/evaporation ratios than those prevailing today, and they may contain shallow lakes, especially during wet years. Considering the definition of the playas and the current situation of Lake Urmia, this lake, too, can be called a playa, the "Urmia Playa", because it meets these criteria, as it has been formed in a closed basin and consists of lacustrine sediments. These barren areas pose potential dangers to the area as they can be the source of salty dust. Since around 2000 , the frequency and the intensity of dust storms in Iran, particularly in western and southwestern regions of the country, have increased remarkably. Dust storms occur with dryness and desertification as well as droughts, which may be the result of the ongoing global warming (Prospero et al., 2002). So far, dust storms in Iran have originated from the neighboring countries, like Iraq and Syria (Zarasvandi, 2009; Moridnejad et al., 2015). Nevertheless, several dried playas of central Iran are also capable of becoming dust generating areas. Many studies have been conducted on playas and their geomorphic surfaces in arid and semi-arid areas. Quite a large number of studies related to the identification of playa surfaces and their properties have been conducted in the USA alone. In the Mojave Desert, 20 playas have been studied and classified based on their surface type (Henley, 1987). These playas have been categorized into two groups: playas with hard and dry surfaces and those with soft and wet surfaces. The results of these studies have revealed that wet saline puffy ground surfaces are prone to generate dust (Goldstein et al., 2017; Rhichards et al., 2007). Reynolds et al. (2009) studied the dust storms data gathered between 2005 and 2008 and their influence on the playa features of the Franklin Playa, the Mojave Desert. Results showed that the higher the dryness of the playa surfaces, the higher the frequency of dust storms. Schreiber et al., (1972) studied Wilcox Playa, southeast of Arizona, and identified such playa surfaces as fan deltas, wet zones, clay flats and salt crusts. Studies in Owens Lake (southeast of California) which is considered to be one of the most important playas in the USA showed that the Owens Playa is an important source of dust generation in the USA (Gill and Cahill, 1992; Quick et al., 2009; Halleaux and Rennó, 2017). Iran, which is located in an arid to semiarid belt, has several playas mostly in its central parts. There have been several studies on playas. One of the earliest and greatest studies ever conducted on Iran's playas belongs to Krinsley (1965-1970). He studied 60 playa surfaces of interior Iran. In his book, Krinsley describes the types of Iran's playa surfaces as salt crusts, clay flats, wet zones, and fan deltas. Krinsley defined seven groups of playas based on the prevailing geomorphic surfaces: clay flat playas, wet clay flat playas, clay flat-salt crust playas, wet dry flat salt crust playas and terminal lake playas. These units were identified from aerial photos (June 1955). Farpour et al., (2011) studied the geomorphic surfaces in Sirjan Playa. They identified different geomorphic surfaces of the Sirjan Playa and described each surface characteristic: saline and nonsaline clay flats, puffy grounds and wet zones. Raisolsadat et al. (2012), in a study of playa deposits in Sahlabad plain, reported that clay flats and salt flats were the most common playa surfaces. Soft and puffy facies, plowed surfaces, clay flats, salt clay polygons and Nabka areas were identified in the clay flat surfaces. Salt flats included clay polygons facies, salt polygons and salt facies. Rashki et al., (2012) studied the changes in Lake Hāmūn water and their influence on dust storms between 1986- 2006, using images from TOMS, MODIS, and MISR satellites and meteorological observations. Results showed that the Lake Hāmūn water level witnessed many fluctuations due to the changes in rainfall during the same years, and these changes affected all the surrounding areas during dust storms.

Although Lake Urmia has been drying for nearly a decade, there have not been many studies related to the Lake Urmia playa and its geomorphic surfaces. Therefore, the aims of this research were to study and detect several geomorphic surfaces of the Lake Urmia playa and to identify their susceptibility to wind erosion.

\section{MATERIALS AND METHODS}

Study area: Lake Urmia is located between $44^{\circ} 50^{\prime}$ to $46^{\circ} 10^{\prime} \mathrm{E}$ longitudes and $36^{\circ} 45^{\prime}$ to $38^{\circ} 20^{\prime} \mathrm{N}$ latitudes in the northwest of Iran. Its surface area used to cover an area of approximately $5000 \mathrm{~km}^{2}$ and even extended up to $6000 \mathrm{~km}^{2}$ during its largest expansion times. Over the past decades, it has shrunk to less than $2000 \mathrm{~km}^{2}$ leaving behind vast barren areas all around it. The study area includes all the lands in the north, northeast, east, southeast and south of Lake Urmia, those which were once part of the lake bed (areas shown in white in Figure 1b). The mean annual precipitation of the Lake Urmia basin is $350 \mathrm{~mm}$. The mean annual temperature varies between $6.5^{\circ} \mathrm{C}$ at higher altitudes to $13.5{ }^{\circ} \mathrm{C}$ at lower altitudes and annual evaporation from the lake varies between 900 and $1170 \mathrm{~mm}$ (Iran Ministry of Energy, 2014). 


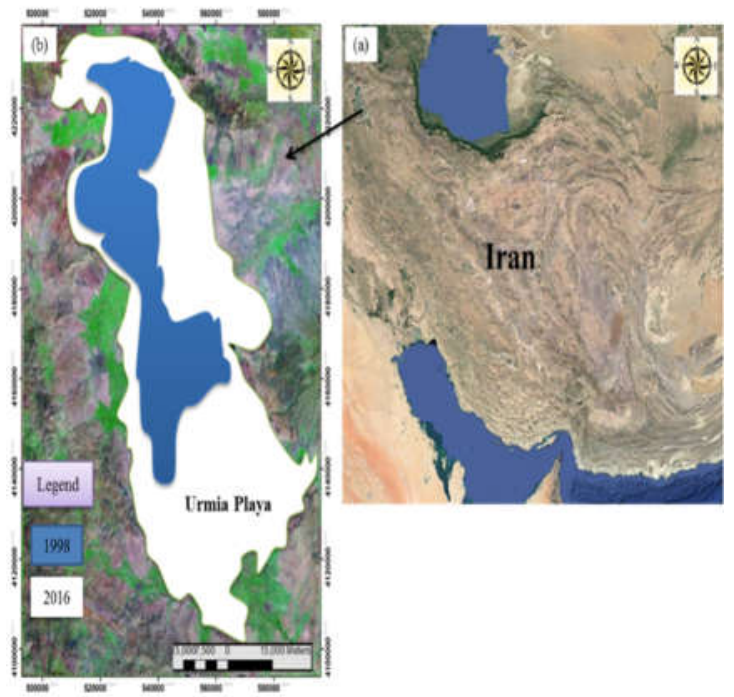

Fig 1. (a): the location of Lake Urmia in the northwest of Iran; (b): Lake Urmia surface area at present (blue) and in the past (white).

According to previous reports, soils in the study area are mainly classified in five Soil Tazanomy Great Groups including Calcixerepts, Haploxerepts, Haploxeralfs, Halaquepts and Endoaquepts (Hamzehpour et al., 2013).

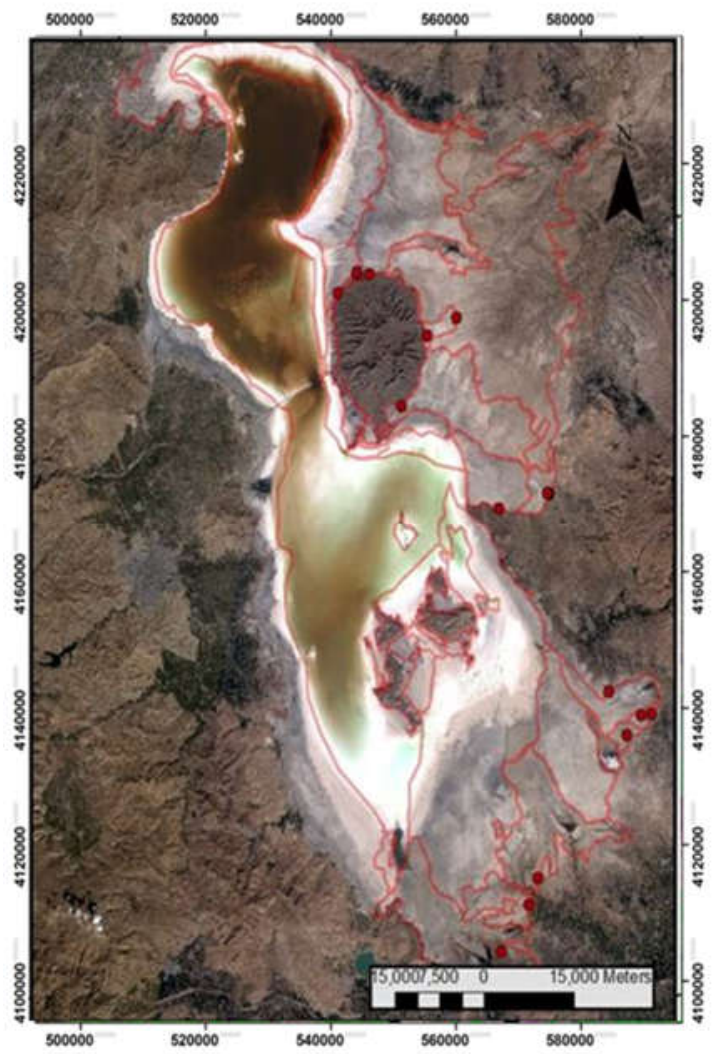

Fig 2. Primary identification of geomorphic surfaces on a 2016 Landsat 8 color composite image and the locations of the sampling points in the study area.
Satellite image studies, field observations and samplings: Landsat7 images of the study area were acquired free of charge from http://earthexplorer.usgs.gov/ for the study area. In order to determine the initial surface area of the lake, satellite images of Lake Urmia form 1998 (the year with the largest expansion of Lake Urmia) were chosen and were compared to those from 2016. In both sets of images, the surface area of Lake Urmia was determined and mapped. Then, by overlaying the images, parts of Lake Urmia which are now uncovered were identified and mapped using ARC GIS 10.4.1 software. ext, several geomorphic surfaces of the Lake Urmia playa were recognized by observing the variation in the gray spectrum using the panchromatic band of Landsat 8 with a resolution of $15 \mathrm{~m}$.

Afterwards, sampling points were chosen on the satellite images by noting the variations in the surface area of the geomorphic surfaces and their dominance (Figure 2). Then, all determined surfaces were checked and verified during field observations, and soil samples were taken from $0-5 \mathrm{~cm}$ of the soil surface. Then, certain physical properties of the samples such as soil texture (hydrometer method), bulk density, saturation percentage, soil color (Munsell color book), soil consistency, soil aggregate distribution, and soil stability (Nimmo and Perkins, 2002) were measured. Then, the correlations between soil properties and each geomorphic surface resistance to wind erosion were determined. Finally, the boundaries between different geomorphic surfaces were drawn and the map of the Lake Urmia playa surfaces was prepared for the study area.

\section{RESULTS AND DISCUSSION}

Geomorphic surfaces identification and nomenclature: In order to name the identified geomorphic surfaces, five indices were used. In Table 1 , a summary of the symbols representing the indices used for the naming of the identified geomorphic surfaces and their definitions are presented. In each surface name, the first symbol represents the type of the playa surface, the second represents the soil texture, the third shows soil resistance to wind erosion, the forth is representative of soil color, and the last shows whether the surface was wet or dry at the time of sampling.

Geomorphic Surfaces: The map of the studied playa surfaces and their related textural classes are represented in figure 6 . Based on the field observations and studies, six types of playa surfaces and abandoned agricultural lands were identified 
These surfaces included sandy and gravel flats, claysalt clay flats, sandy-salt crusts, puffy grounds, delta fans, and wet zones.

Agricultural lands and shrub-grass zones: Due to the recent global drought, mismanagement of lands and overgrazing of livestock in certain parts of the study area, both native and cultivated vegetation cover has been destroyed (Figures $3 \mathrm{a}$ and $3 \mathrm{~b}$ ). In a limited number of places, remnants of vegetation cover were observed, especially in water paths. The formation of thin and fragile salt-silt crusts on the surface of abandoned agricultural lands has turned them to surfaces which can easily entrain by wind erosion. Even in places with hard and stable crusts, livestock grazing and crust destruction result in uncovered remanence of sand-silt size subsoil with low organic matter and high susceptibility to wind erosion.

Sandy and gravel flats: Sand and gravel flats were the least common, and they were mostly seen at the playa edges. Soil surfaces were erodible in these areas. Nevertheless, because of the gravel cover, they have become stable against wind erosion (Figure 3c).

Clay-Salt clay flats: Clay flats were seen in many parts of the research area, especially in the east and southeast of the lake (Figure 6). These surfaces had low salt contents, fine-grained silt and clay sediments with relatively hard surfaces and deep groundwater ( $>$ 5m) (Figure 3e). These areas are resistant against wind. The major difference between the identified clay flats was their salt contents and depth of the groundwater. Clay flats in the east of Lake Urmia had relatively high salt contents in comparison to the clay flats in the south, but due to deep groundwater tables, they were very stable surfaces. Field observations of these areas over several years and in different seasons verified the results.

In contrast, the clay flats in the southeast had lower salt contents with shallower groundwater. During wet seasons with heavy rainfalls, due to the recharge of the groundwater, the depth of the groundwater decreases, and during dry seasons, evaporation from near surface saline groundwater produces soft surfaces which are more susceptible to wind erosion.

Clay flats with mud cracks were mostly seen in the south and southeast of the lake, especially around river paths and on lowlands with gentle topography (Figure $3 \mathrm{f})$. These surfaces, in general, were covered with unstable saline sediments with broken surfaces where the turned up edges of crusts can be mobilized.
Puffy grounds: Puffy grounds were seen in the northeast and south-southwest of the Lake Urmia playa, where depth of groundwater was very shallow $(<1.5 \mathrm{~m}$ at the time of sampling). In such places, fluctuating groundwater along with capillary processes have kept the playa surface wet and facilitated the precipitation of the low density salt with fluffy structure and high erodibility (Figure 3d). Several researchers have emphasized the importance of fluffy playa surfaces, which are prone to wind erosion (Buck et al., 2011; Joeckel and Ang Clement, 2005; Reynolds et al., 2007). Reynolds et al. (2007) defined playas with sallow groundwater as wet playas where the shallow depth of groundwater allows its evaporation, leaving behind very soft surfaces. Studies have shown that hard clay and silt-rich playas can transform to puffy and soft playas due to capillary movement of shallow groundwater (Adams and Sada, 2014). The Lake Urmia surface area and depth vary seasonally. On the other hand, restoration programs aiming at surface water and groundwater recharge might affect hard clay flats close to brine pools, turning them to soft puffy surfaces with high susceptibility to wind erosion.

Sandy-Salt crusts: Sandy-salt crusts were mostly seen in the north and east of the lake. They are formed of loose sand and puffy salt layers with salt crust at the top. In these places, sandy deposits were seen, and these areas are very susceptible to wind erosion under drought and high wind speed conditions. Based on the results of this research, the sandy-salt surfaces were the most erodible areas with high potential for generating dust storms. However, salt crusts with a finer soil texture and a thick layer of salt at their top are very stable surfaces as long as the groundwater table depth is deep and the deposited salt at the surface stays firm as a result of water evaporation and salt crystallization (Figure $3 \mathrm{~g}$ ).

Delta fans: Delta fans were seen at the northeast and southeast boundaries of the lake. The surface of delta fans in the southeast of the lake had fine-grained soil with high water table levels. Once they lose their humidity, they will be erodible and susceptible to wind erosion.

Wet Zones: Wet zones were seen in the east and southeast of the Lake Urmia playa (Figure 3h). Wet zones in these areas were formed of coarse-grained sandy and saline soil, which was stable against wind erosion. The exceptions were the wet zones at the east margin of the lake, which were formed of beach sand with less stability, and consisted of saline deposits with high potential for generating dusts. 

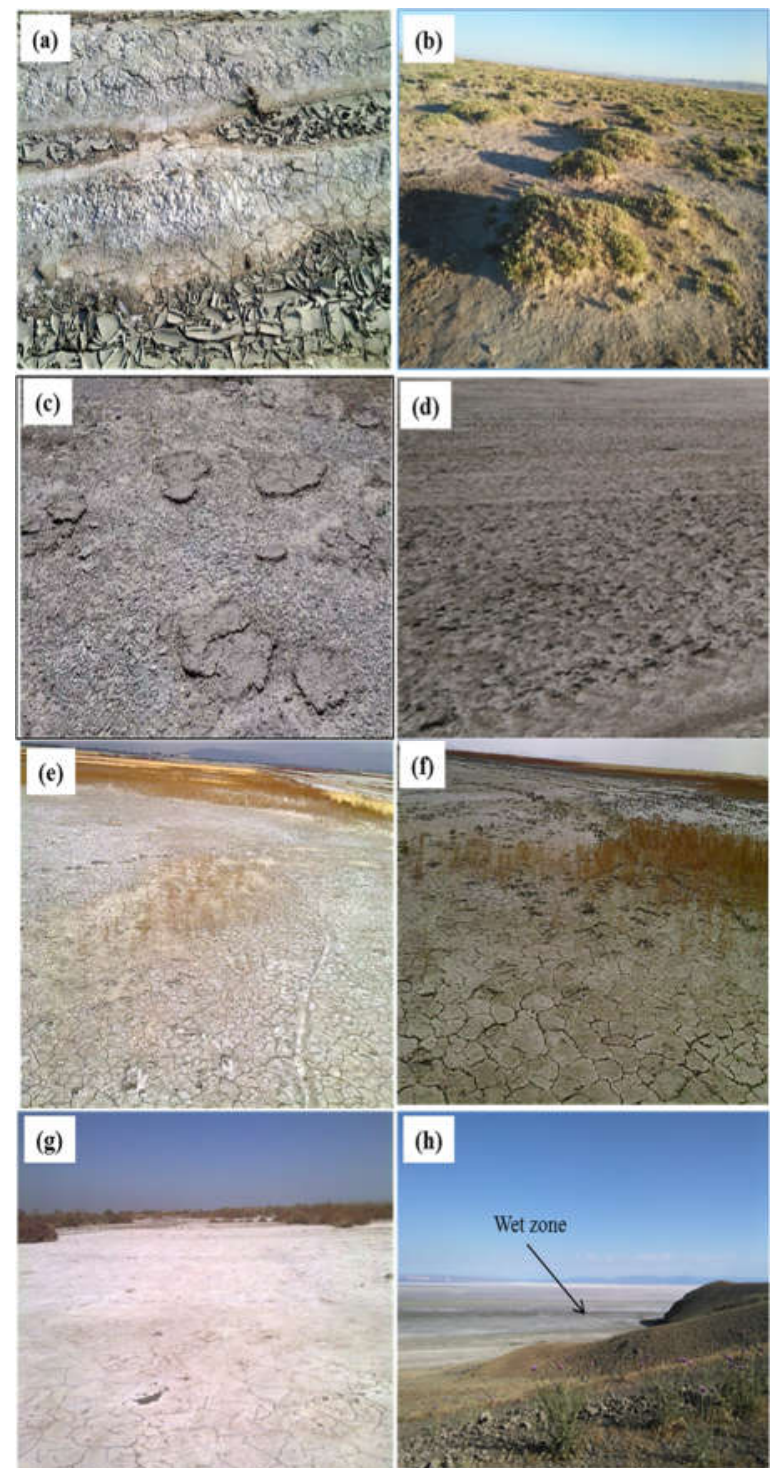

Fig 3. The identified geomorphic surfaces of the Lake Urmia playa. (a) abandoned agricultural land; (b) overgrazed zone; (c) sandy and gravel flat; (d) puffy grounds; (e) clay-salt clay flats; (f) clay flats with mud cracks (g) salt crust; (h) wet zone

Soil texture classes: The location of sampling points on the soil texture triangle is presented in Figure 5. According to soil texture classes, the studied surfaces are divided into three textural groups: 1- loamy sandsandy loam group,

2- silt-loam group, and 3- clay and clay-loam group.

As seen in Figure 5, the study area included a wide range of soil texture classes, from very fine to coarse textures. In some places, where two soil samples were taken (one from the surface and the other form the subsurface of the soil), the surface samples had a texture class of sandy loam, while the subsurface samples, belonged to clay and silt textural classes. Based on the results, approximately $35 \%$ of the soil surfaces in the study area had loam-sandy loam texture with medium to coarse grain sizes, and about $50 \%$ of the soil surfaces had silty loam textures with fine grains. Also, approximately $15 \%$ of the surfaces had clay and clay-loam textures with very fine grains. In the south and southeast of the lake, deposits of sandy loam and sands with medium to coarse grains were found (Figure 4). These areas are mostly located along the river streams, where the rivers finally enter the playa. Fine grain sediments, like clay loam and silt loam texture classes, were rarely seen in the south of the lake, but in the northeast of the playa, they were the most common texture classes. At playa margins, coarse textures along with gravels and stones were observed (Figure 4). These areas belong to Lake Urmia's old beach deposits during the largest expansion times of the lake.

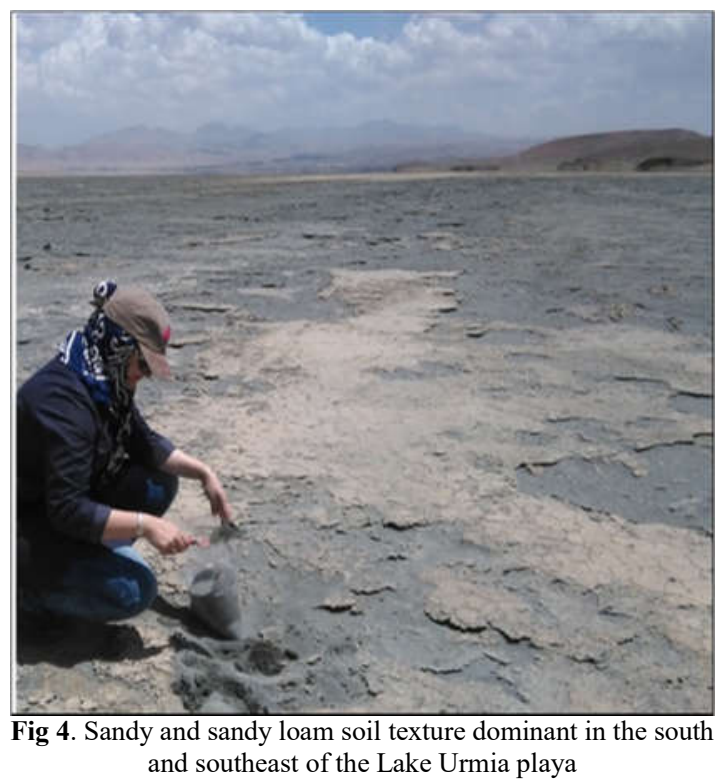

It can be concluded from Figure 6 that the clay-clay loam soil textural group was the least common in the study area and was associated with puffy grounds of the northeast, and a small area of clay flat in the east of the Lake Urmia playa. The silt-silt loam textural group was the most commonly seen textural class in the area, prevailing almost all around the lake, in the northeast, east, south and southeast of the lake. As saltation, which is one of the key processes in dust emission, happens when particles are in silt size, on condition of weak aggregate stability, these areas could become major sources of dust in the area. Studies in Owens Lake, California, which is one of the most important dust generating playas in the USA, have shown that dust emissions in the form of saltation are the prominent phenomena (Cahill et al., 1996; Gillette et al., 2004). The sandy and sandy loam 
textural class was also a common textural group and was seen in the east, southeast and south of the lake.

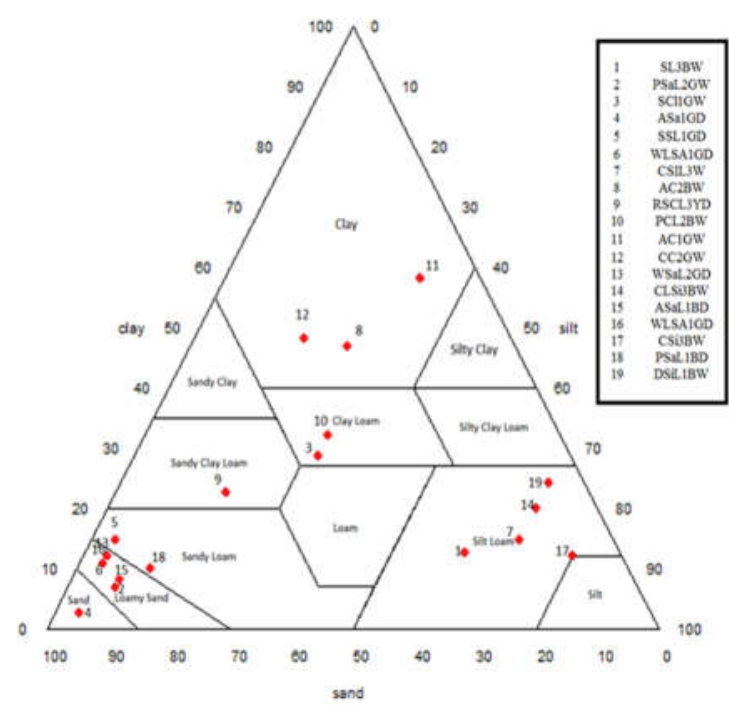

Fig 5. Texture triangle plotting the percentage of sand, silt and clay of the geomorphic surfaces in the Lake Urmia playa.

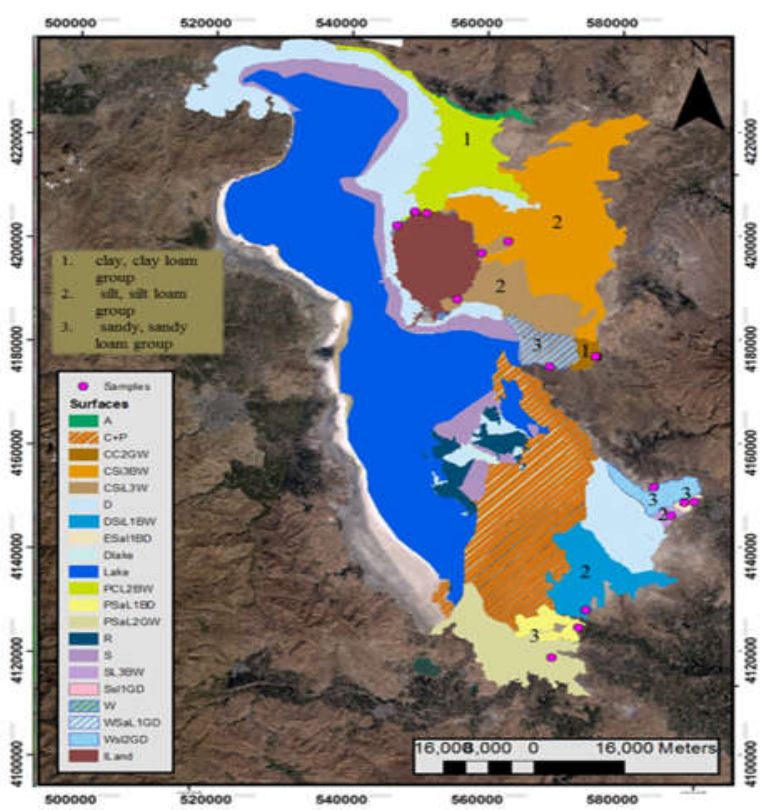

Fig 6. The map of the identified geomorphic surfaces of the Urmia Playa and their related soil texture class

Physical and mechanical properties: A summary of the physical and mechanical properties of the studied geomorphic surfaces are presented in Table 2. Based on these results, most of the soil samples in the study area were weak against external factors and susceptible to wind erosion. Some of the surfaces had very high contents of water and salt. If these surfaces become dry, they will simply change into erodible surfaces.
Soil aggregate stability and distribution: Results from the soil aggregate size distribution and stability studies of the Lake Urmia playa surfaces are presented in Figures 7 and 8, respectively. Based on the major geomorphic surfaces which are identified in the study area (Figure 6), the aggregate stability and distribution curves are presented in five different groups, with each part in Figures 6 and 7 belonging to certain geomorphic surfaces.

Group 1, salt crust (Figures 7 and 8, parts a): These areas had fine to medium aggregate size classes with relatively high stability, due to their high salt contents observed in the field (Figure 3g).

Group 2, puffy grounds and wet zones (Figures 7 and 8 , parts b): These areas had aggregates of fine to medium size with medium to low stability (Figure 3d). Group 3, clay flats (Figures 7 and 8, parts c): In clay flat areas, soil aggregates had fine to medium sizes with rather high stability due to the high clay contents and their strong coherence to each other.

Group 4, delta fans, agricultural lands and lands with gravel (Figures 7 and 8, parts d): Agricultural lands which are now abandoned due to either water scarcity or their secondary salinization with irrigation water or groundwater are areas with low stability and high susceptibility to wind erosion. In this group, RSCL1YD is the eroded surface, which is now stable due to the formation of desert pavement and gravel cover over the surface of the area.

Group 5, delta fans, wet zones and agricultural lands (Figures 7 and 8, parts e). These areas had very weak stability and high erodibility potential in comparison to group 4 .

In Figure 8, the map of the surface stability of the identified geomorphic surfaces is presented. According to Figure 8, the most stable parts of the study area are lands in the eastern parts of the Eslami Island (east Lake Urmia) and a small area in the southeast of Lake Urmia (shown with 1 in the Figure 8). Areas with medium stability are in the northeast, south and southeast of the lake.

The least stable areas are in the south of Lake Urmia, adjacent to the Miandoab Plain, which is the biggest plain in the area. The presence of such susceptible areas close to agricultural lands is a great threat to sustainable agricultural production and also to the health and economy of the great population whose livelihood depends on agriculture. Sweeny et al. (2016) reported that surfaces with aggregates of loose sand size are capable of generating dust several times higher in magnitude than playa surfaces, as aggregates break apart during saltation. 


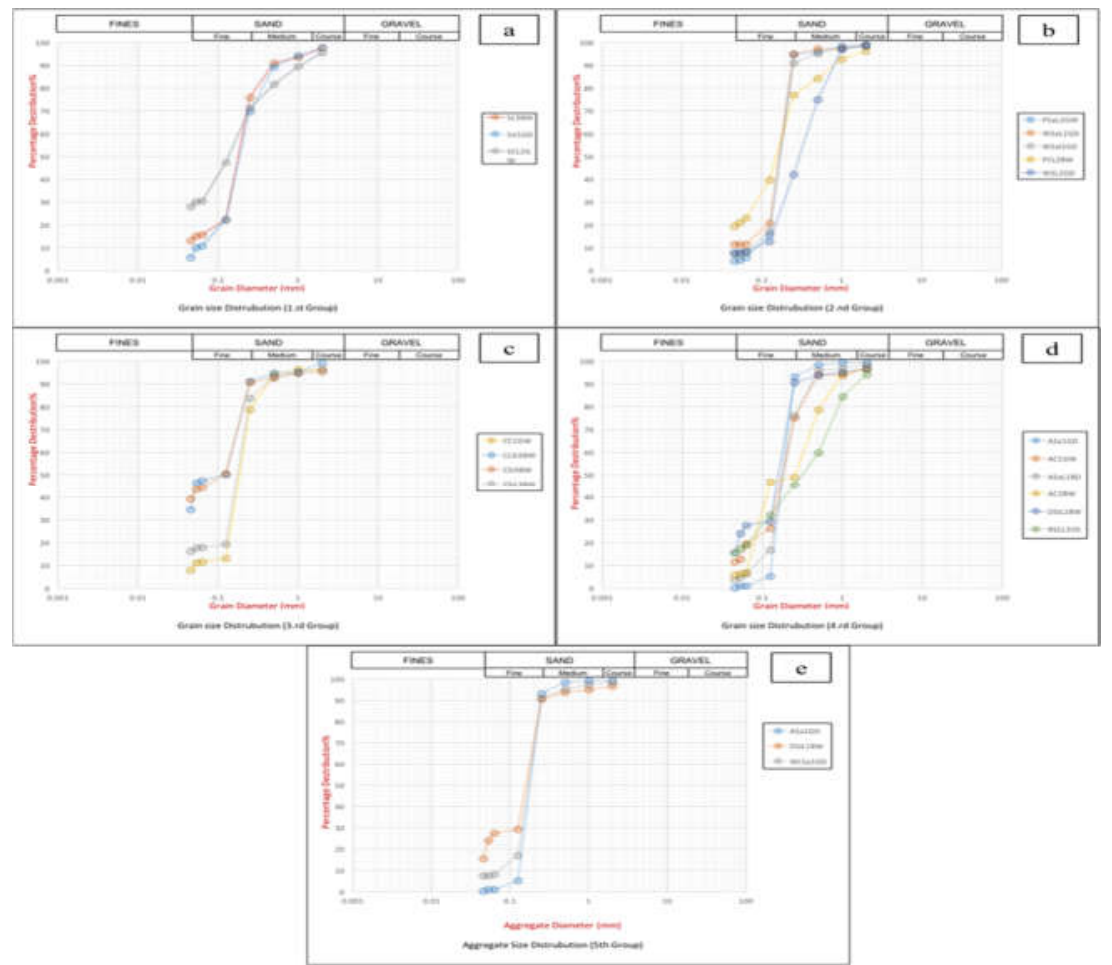

Fig 7. Aggregate size distribution curves for representative soil samples from several identified geomorphic surfaces in the Urmia Playa. Each part represents soil samples' aggregate size: a: salt crusts; b: puffy grounds and wet zones; c: clay flats; d: delta fans, agricultural lands and areas with gravel; e: agricultural lands, wet zones and delta fans

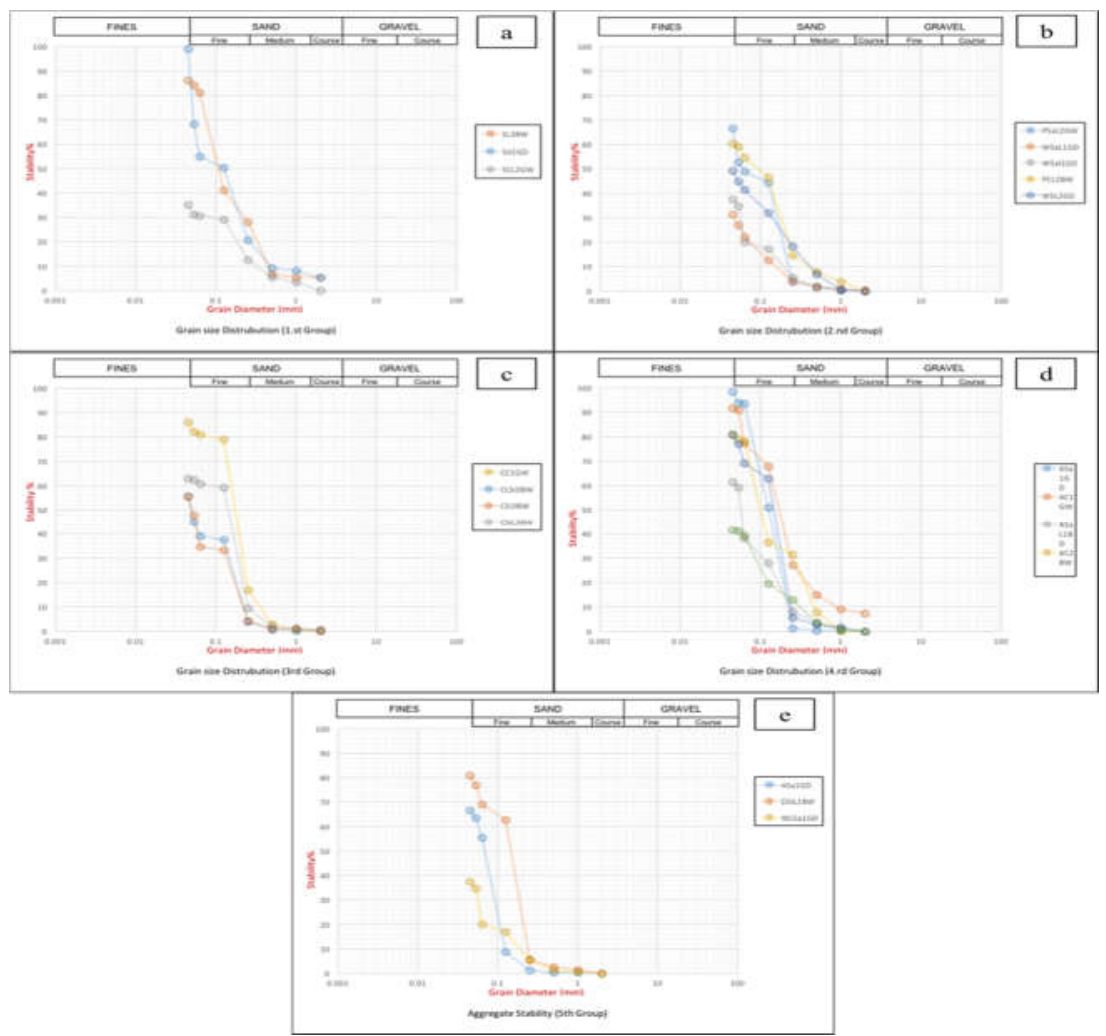

Fig 8. Aggregate stability curves for representative soil samples from several identified geomorphic surfaces in the Urmia Playa. Each part represents soil samples' aggregate stability: a: salt crusts; b: puffy grounds and wet zones; c: clay flats; d: delta fans, agricultural lands and areas with gravel; e: agricultural lands, wet zones and delta fans 


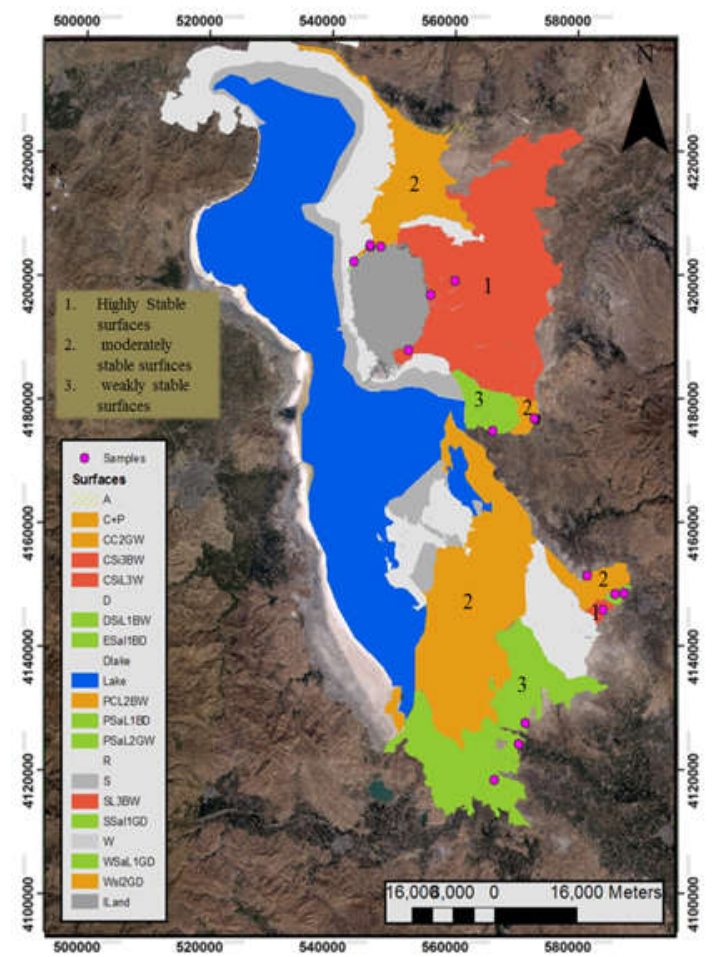

Fig 9. The Urmia Playa surface stability map. Identical colors represent geomorphic surfaces with similar stability.

As sandy-sandy loam texture was observed in the east, southeast and south of the Urmia playa (Figure 4 and $6)$, these areas pose potential dangers in the area. The same study by Sweeny et al. (2016) showed that parts of the Yellow Lake Playa in Texas, where shallow groundwater with proper conditions for the crystallization of efflorescent are available, are also capable of dust emissions with high magnitudes.

These surfaces are reported to be highly susceptible to dust emission in Franklin Lake, Soda Lake and West Cronese Lake playas in the Mojave Desert in California (Reynolds et al., 2007). Puffy grounds of the northeast, east, south and southeast of the Urmia playa with shallow groundwater could also become dust sources in the area, especially where groundwater tables fluctuate seasonally.

Conclusion: The results of this research showed that although it is not long since the Lake Urmia recession started, several geomorphic surfaces including sandy and gravel flats, clay-salt clay flats, sandy-salt crusts, delta fans and wet zones have developed along the northern to the southern shores of the Lake Urmia playa. In geomorphic surfaces adjacent to the northern margins of the Lake Urmia playa, salt contents increase and soil texture becomes coarser and more unstable in comparison to clay flats.
On the other hand, in the east and southeastern parts of the playa, moving from the outer playa towards the center of the playa, surfaces become more stable with finer-grained soils and thicker clay flats or salt crusts at the top. Soil aggregate size distribution curves showed that most of the soil sample aggregate sizes are between medium to fine, which could be well explained by the texture classes of the samples, which were mostly sandy-sandy loam. Due to the large size of the particles, the inner forces which bind particles together to make aggregates of lager sizes become weak, and therefore the size of the aggregates becomes small.

The soil aggregate stability results showed that most of the samples had a medium to low stability, and if winds blow, the soil surfaces will be erodible and will have the potential of generating dusts. According to the results of this research, about $35 \%$ of the geomorphic surfaces of the Lake Urmia playa were strongly susceptible to wind erosion with high potential for generating saline dusts and sand storms. These areas were located in the east and southeast of the lake. Also, $40 \%$ of the playa surfaces with hard salt crust-clay flats had moderate resistance to wind erosion. However, these areas can transform to puffy and soft surfaces due to capillary movements of shallow groundwater. This can happen as a result of the Lake Urmia surface area variations and surface water and groundwater recharge, leading to the instability of the formed hard salt crusts-clay flats. The results also showed that about $25 \%$ of the surfaces had a high resistance to wind erosion, and therefore they do not have any potential for generating dust. In conclusion, the sandy-salt surfaces in the east and southeast of the lake are the most susceptible to wind erosion with high potentials for generating dust, sand, and salt storms, which can affect agricultural lands in the near future. Therefore, their proper management and stabilization should be of high priority.

\section{REFERENCES}

Adams, K.D. and D.W. Sada, 2014. Surface water hydrology and geomorphic characterization of a playa lake system: Implications for monitoring the effects of climate change. Journal of Hydrology 510: 92-102.

Buck, B.J., J. King, V. Etyemezian, 2011. Effects of salt mineralogy and dust emissions, Salton Sea, California. Soil Science Society of American Journal 75: 1958-10972.

Cahill, T.A., T.E. Gill, J.S. Reid, E.A. Gearhart, D.A. Gillette, 1996. Saltating particles, playa crusts and dust aerosols at Owens (dry) Lake, California. 
Earth Surface Processes and Landforms 21, 621639.

Chen, B., H. Kitagawa, K. Hu, D. Jie, J. Yang, J. Li, 2009. Element and mineral characterization of dust emission from the saline land at Songnen Plain, Northeastern China. Journal of Environmental Sciences 21(10): 1362-1370.

Farokhnia, A., S. Morid, 2014. Assessment of the effect of temperature and precipitation variations on the trend of river flows in Urmia Lake watershed. Journal of Water Wastewater 25(91): 86-97.

Farpour, M.H., M. Neyestani, M.K. Eghbal, I.E. Borujeni, 2012. Soil-geomorphology relationships in Sirjan Playa, south central Iran. Geomorphology 138: 223-230.

Gill, T.E., T.A. Cahill, 1992. Playa-generated dust storms from Owens Lake. In The History of Water: Eastern Sierra Nevada, Owens Valley, White Inyo Mountains. University of California Press, Los Angeles, 63-73.

Gillette, D., D. Ono, K. Richmond, 2004, A combined modeling and measurment technique for estimating windblown dust emissions at Owens (dry) Lake, California. Journal of Geophysical Researchs, 109, F01003.

Ginoux, P., J.M. Prospero, T.E. Gill, N.C. Hsu, M. Zhao, 2012. Global-scale attribution of anthropogenic and natural dust sources and their emission rates based on MODIS Deep Blue aerosol products. Reviews of Geophysics, 50, RG3005.

Goldstein, H.L., G.N. Breit, R.L. Reynolds, 2017. Controls on the chemical composition of saline surface crusts and emitted dust from a wet playa in the Mojave Desert (USA). Journal of Arid Environments 140: 50-66.

Halleaux, D.G., N.O. Rennó, 2014. Aerosols-climate interactions at the Owens "Dry" Lake, California. Aeolian Research 15: 91-100.

Hamzehpour, N., P. Bogaert, 2017. Improved spatiotemporal monitoring of soil salinity using filtered kriging with measurement errors: An application to the West Urmia Lake, Iran. Geoderma 295: 23-33.

Hamzehpour, N., M.K. Eghbal, B. Bogaert, N. Toomanian, R.S. Oskoui, 2013. Spatial prediction of soil salinity using kriging with measurement errors and probabilistic soft data. Arid Land Research and Management 27(2): 128-139.

Hassanzadeh, E., M. Zaeghami, Y. Hassanzadeh, 2012. Determining the main factors in declining the Urmia Lake level by using system dynamics modeling. Water Resource Management 26(1): 129-145.

Henley, J.P., 1988. Methods of determining playa surface conditions using remote sensing. U.S. Army Corps of Engineer, Topographic Engineering Center, Arlington, VA, USA. Report R-135.

Hoseinpour, M., A.F. Naghili, 2010. Death of Urmia Lake, a Silent Disaster Investigating of causes, results and solutions of Urmia Lake drying. The 1 st International Applied Geological Congress, Department of Geology, Islamic Azad University - Mashad Branch, Iran.

Iran Ministry of Energy, Deputy of Water and Wastewater, Macro Planning Bureau. 2014. The National Water Master Plan Study in the Aras, Sefidrood, between Sefidrood and Haraz, Atrac and Urmia: agricultural water use study in Urmia Lake Basin. Report Number: 2385070-442019464.

Joeckel, R.M., B.J. Ang Clement, 2005. Soils, surficial geology and geomicrobiology of saline-sodic wetlands, North Platte River Valley, Nebraska, USA. Catena 61: 63-101.

Kakahaji, H., H.D. Banadaki, A. Kakahaji, 2013. Prediction of Urmia Lake water-level fluctuations using analytical, linear statistic and intelligent methods. Water Resource Management 27(13): 4469-4492.

Karbassi, A., G. Bidhendi, A. Pejman, M. Bidhendi, 2010. Environmental impacts of desalination on the ecology of Lake Uromia. Journal of Great Lakes Research 36(3): 419-424.

Krinsley, D.B. 1970. A geomorphological and paleoclimatological study of the playas of Iran. U.S. Geological Survey. U.S. Government Printing Offic, contract. PROCP 700-800. US Air Force Cambridge Research.

Middleton, N.J., 2017. Desert dust hazards: A global review. Aeolian Research, 24, 53-63. 
Moridnejad, A., N. Karimi, P.A. Ariya, 2015. Newly desertified regions in Iraq and its surrounding areas: Significant novel sources of global dust particles. Journal of Arid Environments 116: 110.

Nimmo, J.R., K.S. Perkins, 2002. Aggregate stability and size distribution. In: Dane JH, Topp GC, editors. Methods of soil analysis, Part 4-Physical methods: Madison, Wisconsin, Soil Science Society of America 317-328.

Prospero, J.M., P. Ginoux, O. Torres, S.E. Nicholson, T.E. Gill, 2002. Environmental characterization of global sources of atmospheric soil dust identified with the NIMBUS 7 Total Ozone Mapping Sectrometer (TOMS) absorbing aerosol product. Reviews of Geophysics 40(1): 1002.

Quick, D., M. Reheis, B. Stewart, O. Chadwick, 2009. Impact of One Hundred Years of Owens Lake Playa Dust on Nearby Alluvial Soils. AGU Fall Meeting Abstracts.

Raisossadat, S.N., M.H. Zarrinkoub, M.M. Khatib, 2012. Geomorphology and Genesis of Sahl Abad Playa-East of Iran. Geography and Development 10(28): 31-39.

Rashki, A., D. Kaskaoutis, A. Goudie, R. Kahn, 2013. Dryness of ephemeral lakes and consequences for dust activity: the case of the Hamoun drainage basin, southeastern Iran. Science of the Total Environment 463: 552-564.

Reynolds, R.L., R. Bogle, J. Vogel, H. Goldstein, J. Yount, 2009. Dust emission at Franklin Lake Playa, Mojave Desert (USA): Response to meteorological and Hydrologic changes 20052008. Natural Resources and Environmental Issues 15: 105-115.
Reynolds, R.L., J.C. Yount, M. Reheis, H. Goldstein, P. Chavez, R. Fulton, J. Whitney, Ch. Fuller, R.M. Forester, 2007. Dust Emission from Wet and Dry Playas in the Mojave Desert, USA. Earth Surface Processes and Landforms 32: 1811-1827.

Schreiber, J., G.L. Pine, B.W. Pipkin, R.C. Robinson, J.C. Wilt, 1972. Sedimentologic studies in the Willcox Playa area, Cochise County, Arizona. International Center for Arid and Semi-Arid Land Sudies, In: Reeves, C.C. (Ed). Playa Lake Symposium. pp. 107-133.

SEDAC. 2010. Gridded population of the world: future estimates. Socioeconomic data and applications center (SEDAC); collaboration with CIESIN, UN-FAO, CIAT. Accessed December 14, 2011 at: http://sedac.ciesin.columbia.edu/gpw.

Shadkam, S., . Ludwing, P. van Oel, C. Kirmit, P. Kabat, 2016. mpacts of climate change and water resources development on the declining inflow into Iran,s Urmia Lake. Journal of Great Lakes Research 42(5): 942-952.

Sweeney, M.R., V.A. Zlotnik, R.M. Joeckel, J.E. Stout, 2016. Geomorphic and hydrologic controls of dust emissions during drought from Yellow Lake playa, West Texas, USA. Journal of Arid Environments 133: 37-46.

Zarasvandi, A. 2009. Environmental impacts of dust storms in the Khuzastan Province. Environmental Protection Agency (EPA) of Khuzastan province. Internal report: $375 \mathrm{p}$. 